\title{
On the Need for Standard Definitions and Education to Optimize Patient-Ventilator Interactions
}

In this issue of Respiratory CARE, Ramirez et $\mathrm{al}^{1}$ present the results of their multi-center study. Doctors, nurses, and physiotherapists (akin to a respiratory therapist in Chile) were shown videos of ventilator screens demonstrating different types of asynchrony. The health-care providers had to identify 3 asynchronies (double-triggering, autotriggering, and ineffective triggering) from a multiple-choice test. All asynchronies are clinically relevant because they may cause harm. Only $21 \%$ of the 366 health-care providers studied could identify the 3 asynchronies correctly. Those who had any training on mechanical ventilation did better (30.4\% vs $9.4 \%)$. This low rate of recognition is similar to that in a report by Colombo et al. ${ }^{2}$ As members of the health-care community, we should be concerned. The study highlights several areas where we should improve our performance to deliver safer mechanical ventilation.

The first area for improvement is the establishment of a standard vocabulary and definitions to describe patientventilator interactions. Reviews, trials, and reports use different definitions for asynchrony and its types. ${ }^{2-5}$ This leads to confusion and hinders our ability to determine the incidence and impact of patient-ventilator interactions, their association with each mode of ventilation, and patient outcomes. One such example is the definition of double-triggering. Ramirez et $\mathrm{al}^{1}$ used the definition " 2 consecutive inspirations occurring within an interval of less than half of the mean inspiratory time." We will let the reader be the judge, but we could not understand it as it stands. However, a limited search of the literature yields similar definitions with different terms: "two cycles separated by a very short expiratory time, defined as less than one-half of the mean inspiratory time, the first cycle being patient-triggered"4 or "two ventilator insufflations delivered within one patient inspiratory effort, and the first trigger should be patient-triggered." 5 Which definition is the most correct? They all describe the same process, yet they use very different words; these are confusing and difficult to apply at the bedside.

\footnotetext{
Dr Mireles-Cabodevila is a co-owner of a patent for mid-frequency ventilation. Dr Dugar has disclosed no conflicts of interest.
}

Correspondence: Eduardo Mireles-Cabodevila MD, 9500 Euclid Avenue, G62, Cleveland, OH 44195. E-mail: mirelee@ccf.org.

DOI: $10.4187 /$ respcare. 05452
More troubling is that none of these definitions guide us toward the etiology. This is particularly troubling because the pressure and volume waveforms of autotriggering, reverse triggering, and double-triggering can look the same. ${ }^{5}$ Indeed, the 3 asynchronies have different etiology, but the ventilator is doing the same thing regardless of the cause.

\section{See the Original Study on Page 144}

The ventilator has sensed that a breath must be triggered immediately after the last breath. There is no time for expiration because the trigger threshold is met and the next breath starts immediately upon termination of the refractory period (a short time at the start of exhalation intended by engineers to minimize double-triggering). In other words, the ventilator has sensed that a breath must be triggered immediately after the last breath and delivers another breath, irrespective of whether it was caused by patient effort (double-triggering or reverse triggering) or not (autotriggering). For all of the etiologies, the consequence is that 2 or more mechanical breaths are delivered without sufficient exhalation time, resulting in the same pressure-volume waveforms, yet the management is completely different. A set of standard definitions and vocabulary of terms describing the patient-ventilator interactions are needed to be able to identify patterns, understand etiologies, teach, research, and care for our patients.

This brings us to the second area of improvement as mentioned by Ramirez et al. ${ }^{1}$ Those health-care professionals who had received some mechanical ventilation training did better than the rest. We know that education works; we know that providers can be trained to recognize patient-ventilator interactions. 6,7 The American Association for Respiratory Care task force article ${ }^{8}$ outlining the competencies needed for the future respiratory therapist includes the interpretation of waveforms and improving patient-ventilator synchrony. This is a competency that we need to foster because it has a direct impact on patient outcomes. ${ }^{7,9-11}$ Further research must be done to help us to understand the best method to teach, how often we should teach, and the best teaching venue. Having a standard set of definitions and vocabulary will certainly help educators to deliver consistent messages.

Finally, the study by Ramirez et $\mathrm{al}^{1}$ speaks of the ability to recognize patterns reliably. The present generation of 
mechanical ventilators has powerful microprocessors, sensors, and software that make previous devices pale in comparison. However, no current ventilator has alarms that detect the presence of potentially harmful patient-ventilator interactions. Current ventilators recognize triggering (machine or patient) and could be programmed to report the presence of some types of asynchrony. Newer technological developments and research have demonstrated the ability to effectively detect asynchronies and dysnchronies. ${ }^{4,11}$ This type of technology may take time to permeate to routine patient care but, given its relevance, should top the list of developments. We take this moment to caution that technology does not replace education; one without the other makes us dangerous, but both together make us more effective.

In summary, we commend Ramirez et al ${ }^{1}$ for measuring and reporting the poor recognition of significant patientventilator interactions among health-care providers. Their work highlights the need for a standard vocabulary to help research, improve health-care education, and harness the power of technological developments to improve patient care.

Eduardo Mireles-Cabodevila MD

Respiratory Institute Department of Critical Care Medicine Cleveland Clinic Cleveland Clinic Lerner College of Medicine Case Western Reserve University Cleveland, Ohio

Siddharth Dugar MD Respiratory Institute Department of Critical Care Medicine Cleveland Clinic Cleveland, Ohio

\section{REFERENCES}

1. Ramirez II, Arellano DH, Adasme RS, Landeros JM, Salinas FA, Vargas AG, et al. Ability of ICU health-care professionals to identify patient-ventilator asynchrony using waveform analysis. Respir Care 2017;62(2):144-149.

2. Colombo D, Cammarota G, Alemani M, Carenzo L, Barra FL, Vaschetto R, et al. Efficacy of ventilator waveforms observation in detecting patient-ventilator asynchrony. Crit Care Med 2011;39(11): 2452-2457.

3. Branson RD, Blakeman TC, Robinson BRH. Asynchrony and dyspnea. Respir Care 2013;58(6):973-989.

4. Sinderby C, Liu S, Colombo D, Camarotta G, Slutsky AS, Navalesi $\mathrm{P}$, Beck J. An automated and standardized neural index to quantify patient-ventilator interaction. Crit Care 2013;17(5):R239.

5. Liao KM, Ou CY, Chen CW. Classifying different types of double triggering based on airway pressure and flow deflection in mechanically ventilated patients. Respir Care 2011;56(4):460-466.

6. Chacón E, Estruga A, Murias G, Sales B, Montanya J, Lucangelo U, et al. Nurses' detection of ineffective inspiratory efforts during mechanical ventilation. Am J Crit Care 2012;21(4):e89-e93.

7. Lynch-Smith D, Thompson CL, Pickering RG, Wan JY. Education on patient-ventilator synchrony, clinicians' knowledge level, and duration of mechanical ventilation. Am J Crit Care 2016;25(6):545551.

8. Barnes TA, Gale DD, Kacmarek RM, Kageler WV. Competencies needed by graduate respiratory therapists in 2015 and beyond. Respir Care 2010;55(5):601-616. Erratum in: Respir Care 2010;55(6):789.

9. Chanques G, Kress JP, Pohlman A, Patel S, Poston J, Jaber S, Hall JB. Impact of ventilator adjustment and sedation-analgesia practices on severe asynchrony in patients ventilated in assist-control mode. Crit Care Med 2013;41(9):2177-2187.

10. Thille AW, Rodriguez P, Cabello B, Lellouche F, Brochard L. Patient-ventilator asynchrony during assisted mechanical ventilation. Intensive Care Med 2006;32(10):1515-1522.

11. Blanch L, Villagra A, Sales B, Montanya J, Lucangelo U, Luján M, et al. Asynchronies during mechanical ventilation are associated with mortality. Intensive Care Med 2015;41(4):633-641. 